\title{
EPIDEMIOLOGICAL ANALYSIS ON ACETABULAR FRACTURES
}

Maurício Silveira Maia', Denise Cristina Montecchio Santos², Daniel Magalhães de Queiroga ${ }^{3}$, Claydson de Oliveira Castro², Rebeca Macedo Fraga e Silva ${ }^{2}$, Aliny Cristine Brito Reis ${ }^{2}$, Aline Cristina Ducatti ${ }^{4}$

\section{ABSTRACT}

This aim of this work was to carry out an epidemiological study on acetabular fractures in the city of Campinas and surrounds, in view of the few published papers on this subject. Medical files with a diagnosis of acetabular fracture between the years 2004 and 2008 that were made available by the Medical Archiving Service of Hospital das Clínicas, State University of Campinas (UNICAMP) were analyzed by six observers. Data on patients' ages, sex, side affected by the fracture, mechanism of injury, material used for syn- thesis, complications of the operation, associated fractures, length of hospitalization before and after the surgery, time of total internment and number of physiotherapy sessions before and after the surgery were gathered. It was observed in this population that the left side was more affected; the mechanism of injury that most often caused this type of fracture was automobile accidents; injuries to the sciatic nerve were the commonest surgical complications; and the synthesis material most used was reconstruction plates.

Keywords - Epidemiology; Acetabulum; Bone Fractures

\section{INTRODUCTION}

Fractures of the acetabulum are generally very serious, since they are associated with high speed and high-energy trauma, such as in vehicle accidents, and often occur in multiple trauma patients. Over the years, treatment of this type of fracture has been a challenge to surgeons because they are located in a region that is difficult to access; there is a lack of reduction techniques; few implants are available for fracture fixation; and the patients' clinical condition is highly complex. Hence, conservative treatment is considered to be the preferred approach, because it is safer.

The techniques for treating acetabular fractures have become more refined through the studies of Judet and Letournel, which have contributed towards surgical advances and have provided for physiotherapeutic action for these patients' rehabilitation. This has enabled early mobilization of this joint after the surgery. Implementing physiotherapy both before and after the operation is of fundamental importance for these patients' respiratory and motor functions, thereby making early hospital discharge possible ${ }^{(1)}$.

1 - Physiotherapist; Specialist in Physiotherapy for Orthopedics and Traumatology from Campinas State University (UNICAMP); Specialist in Sports Physiotherapy from the Federal University of São Paulo (UNIFESP). Postgraduate Specialization Student of Physiotherapy for Orthopedics and Traumatology, State University of Campinas.

2 - Postgraduate Specialization Student of Physiotherapy for Orthopedics and Traumatology, State University of Campinas.

3 - Physiotherapist at CLIFIM Clinic, Jaguariúna, SP. Postgraduate Specialization Student of Physiotherapy for Orthopedics and Traumatology, State University of Campinas.

4 - Physiotherapist at the Municipal Authority of Uberlandia, MG. Postgraduate Specialization Student of Physiotherapy for Orthopedics and Traumatology, State University of Campinas.

Work performed at Hospital das Clínicas, State University of Campinas (UNICAMP)

Correspondence: Rua Irarié Quadra 07 - lote 06 - Parque Acalanto - 74860-140 - Goiânia, GO.

E-mail: mauriciosilveiramaia@gmail.com

Work received for publication: December 4, 2009; accepted for publication: July 19, 2010. 
The aim of this study was to make an epidemiological analysis on cases of acetabular fracture attended at Hospital das Clínicas, State University of Campinas (Unicamp) between 2004 and 2008.

\section{METHODOLOGY}

A retrospective study was conducted in the city of Campinas, State of São Paulo, among male and female patients hospitalized in Hospital das Clínicas, State University of Campinas (Unicamp), with a diagnosis of acetabular fracture between 2004 and 2008.

For the purposes of this study, data were gathered between December 1 and 20, 2008, through analysis on medical files held at the medical archiving service. Six observers gathered data on patients' ages, sex, side affected by the fracture, injury mechanism, synthesis material used, complications during the operation, associated fractures, length of hospital stay before and after the operation, total duration of hospital stay and numbers of physiotherapy sessions undertaken before and after the surgery.

To analyze the data, the Microsoft Office Excel 2007 software was used. The data were expressed as means and standard deviations, and were then correlated using percentages and graphical comparisons.

\section{RESULTS}

The medical files of 69 patients were evaluated. Seventy-one cases of acetabular fracture were found and, among these, $85.5 \%$ were in men and only $14.5 \%$ were in women (Figure 1). The mean age among the population analyzed was 33 years, with a range from 16 to 66 years.

The side that was more commonly affected by a fracture was the left side, such that $57.7 \%$ (41) of the patients presented a fracture in the left-side ace-

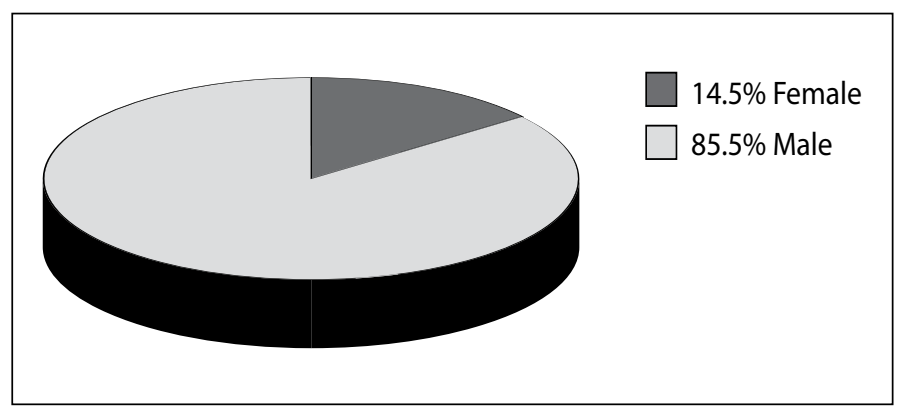

Figure 1 - Correlation between acetabular fractures and gender.

Rev Bras Ortop. 2011;46(1):23-6 tabulum, while 42.3\% (30) presented a fracture in the right-side acetabulum (Figure 2). Occurrences of hospitalization at Hospital das Clínicas due to acetabular factures increased over the years (Figure 3). There was no difference in prevalence between the months of the year.

The injury mechanism that was most responsible for acetabular fractures was car accidents, which accounted for $46.37 \%$ (32), followed by motorcycle accidents $(31.88 \% ; 22)$ and falls $(8.69 \% ; 6)$ (Figure 4$)^{(3,4)}$.

The mean duration of the hospital stay before the operation was 9.7 days, and the mean hospital stay after the operation was 11.42 days.

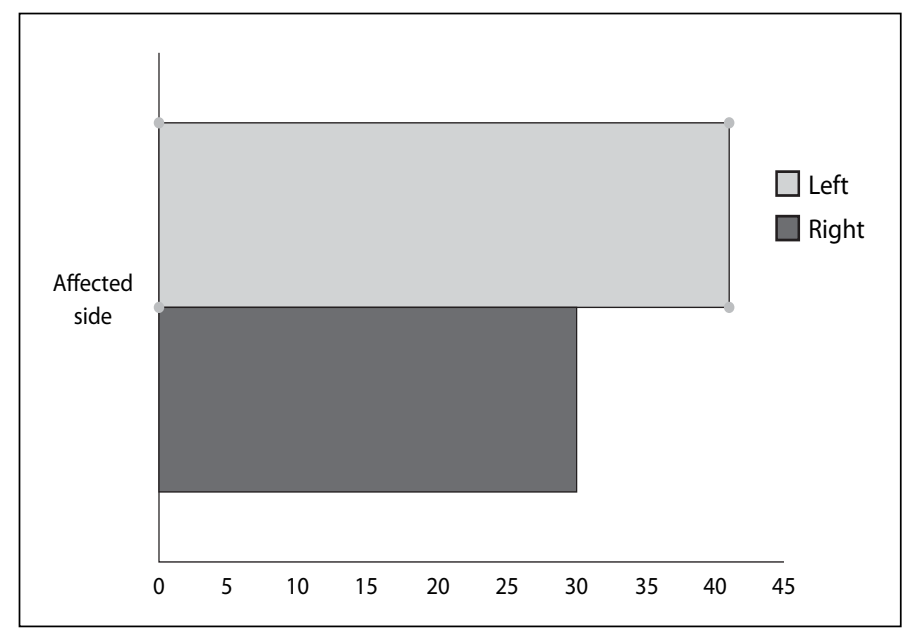

Figure 2 - Correlation between acetabular fractures and the affected side.

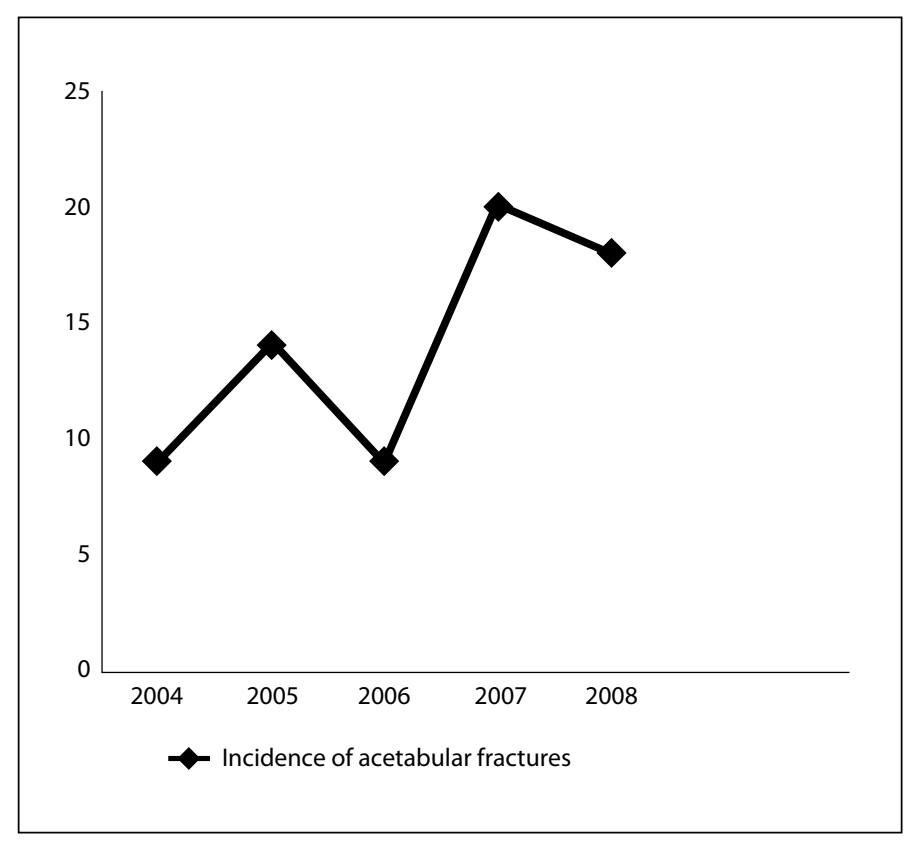

Figure 3 - Incidence of acetabular fractures per year. 


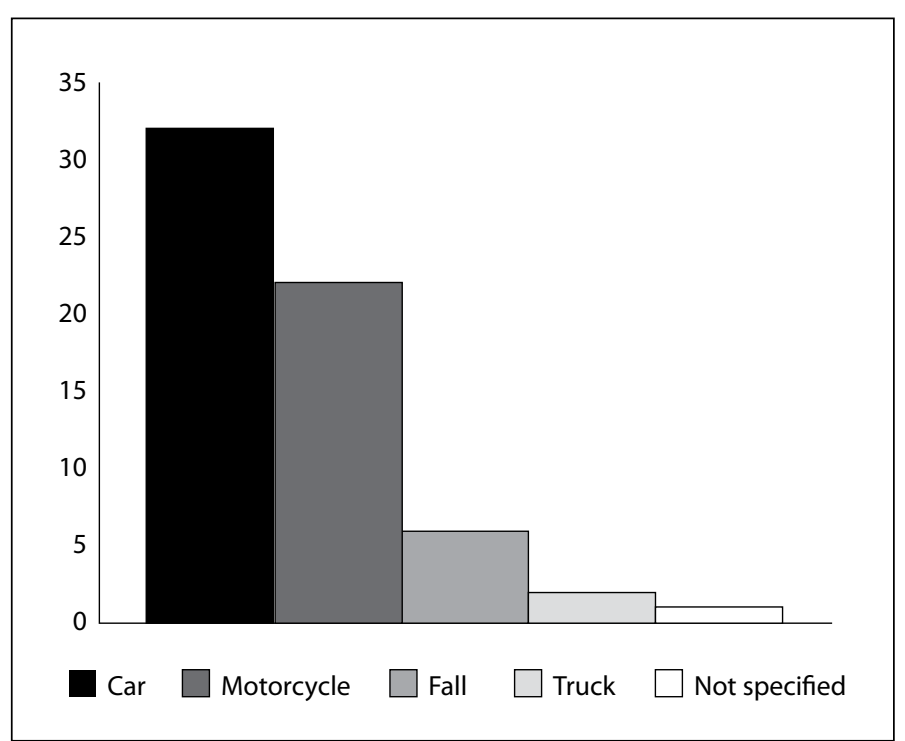

Figure 4 - Incidence of mechanisms of injury.

In this study, diagnoses of lesions of the sciatic nerve were made in three patients $(4.34 \%)$, infections in two patients $(2.89 \%)$ and pulmonary thromboembolism and cardiac complications in one patient (1.44\%) (Figure 5).

Among the synthesis materials used for the surgical correction, the largest proportion were reconstruction plates, in $70.45 \%$ (62), followed by one-third tubular plates in $22.72 \%$ (20) and dynamic compression plates in 6.81\% (6) (Figure 6).

The mean number of preoperative physiotherapy sessions was 4.28 , with a maximum of 22 and minimum of zero. The mean number of postoperative sessions was 8.43 , with a maximum of 96 and minimum of zero.

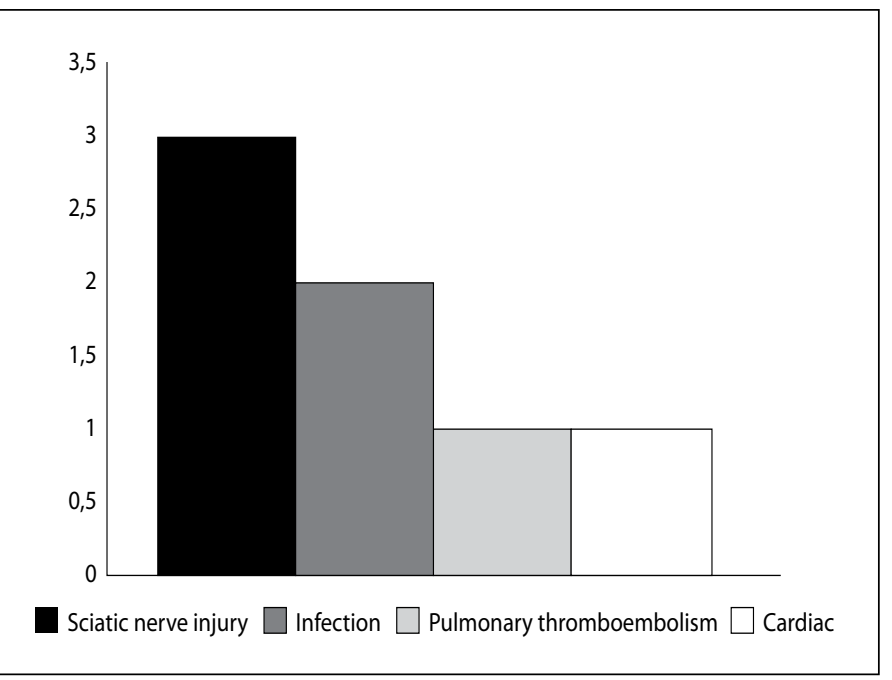

Figure 5 - Postoperative complications.

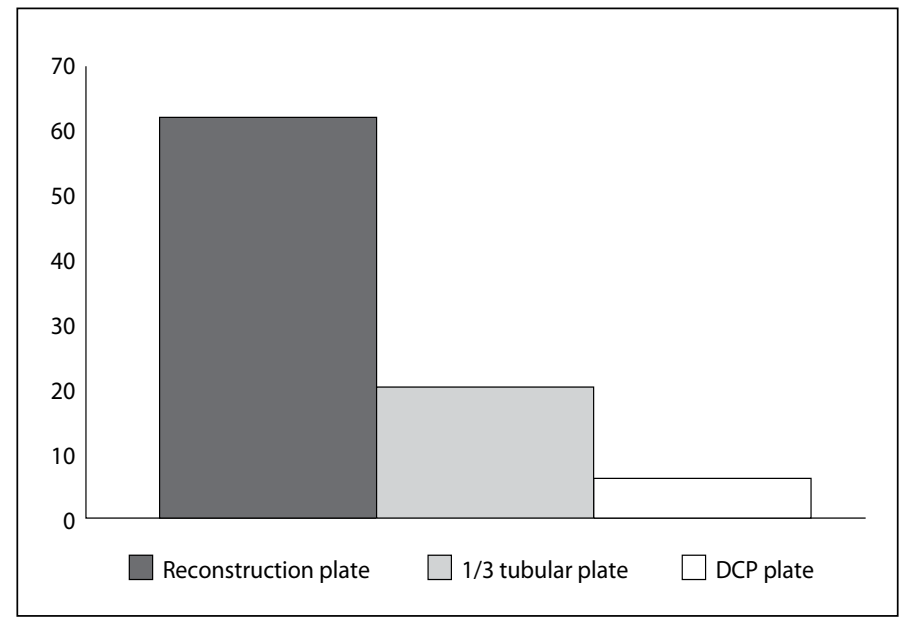

Figure 6 - Types of osteosynthesis.

\section{DISCUSSION}

Most of the patients who suffered a fracture of the acetabulum were male. This corroborates the previous studies $^{(2,3)}$, which also found greater incidence among males.

The mean age among the patients (33 years) was close to what was found in the study by Kumar et $\mathrm{al}^{(3)}$, in which the mean age observed was 39.5 years. It was not possible to establish a motive for the predominance of fractures on the left side, but we would suggest that this difference is not significant, given that it was possible for both sides to be affected.

Acetabular fractures are classified according to Judet and Letournel apud Beaulé et $\mathrm{al}^{(1)}$ as either simple or in association. Simple fractures include: anterior wall, anterior spine, posterior wall, posterior spine and transverse fractures. Associations of fractures include: $\mathrm{T}$, anterior wall or posterior spine with semi-transverse posterior fractures; transverse with posterior wall fractures; posterior spine with posterior wall fractures; and anterior spine with posterior spine fractures. This classification makes it possible to choose the appropriate surgical technique, and to correlate this with possible lesions in the tissues surrounding the fracture site, such as nerve and vascular lesions.

As observed, the increasing incidence over the years suggests that traffic accidents are increasingly caused by high-energy collisions. Most accident victims suffer multiple trauma and acetabular fractures, but there is no hard evidence in this respect.

Vehicle accidents were responsible for the higher 
rate of acetabular fractures, just as in the studies by Kumar et $\mathrm{al}^{(3)}$ and VanOpdorp et $\mathrm{al}^{(4)}$.

VanOpdorp et $\mathrm{al}^{(4)}$ reported that for surgical correction of acetabular fractures to be successful, it should be done within the first 14 days. In the present study, the mean time that elapsed was within this expected limit (9.7 days).

Acetabular reconstruction surgery is subject to complications, among the following can be highlighted: nerve or vascular lesions, thus correlating the nerve and the artery with the access route used; thromboembolism; infections; and late complications such as heterotopic ossification and osteodystrophy ${ }^{(4-6)}$. In the present study, sciatic nerve lesions, infections, pulmonary thromboembolism and cardiac complications were found.

There were discrepancies in the numbers of physiotherapy sessions, both before and after the operation. This can be explained by the fact that the patients who underwent acetabular reconstruction had suffered multiple trauma. Thus, the sample was very heteroge- nous, which made it impossible to correlate the effect of physiotherapy with the duration of hospital stay.

\section{FINAL REMARKS}

From the data presented, it could be concluded that the sample only represented the Campinas region and its surrounds, since this was not a multicenter study. A larger proportion of the acetabular fractures occurred among males, and the left side was more affected. The injury mechanism that caused most of these fractures was vehicle accidents, which shows that acetabular fractures are highly correlated with high-energy trauma.

The synthesis material most used among this population was reconstruction plates, followed by one-third tubular plates.

It was not possible to correlate any greater incidence of accidents with any specific months of the year. The patient sample analyzed was very heterogenous, which meant that it was impossible to correlate the physiotherapy with optimization of hospital discharge.

\section{REFERENCES}

1. Beaulé PE, Dorey FJ, Matta JM.. Letournel Classification for Acetabular Fractures: Assessment of interobserver and intraobserver reliability. J Bone Joint Surg Am. 2003;85(9):1704-9.

2. Barbosa ALH, Schutz PC, Pavan L. Tratamento cirúrgico das fraturas de acetábulo: estudo retrospectivo de 48 casos. Acta Ortop Bras. 2000;8(3):140-3

3. Kumar A, Shah NA, Kershaw SA, Clayson AD. Operative management of acetabular fractures: A review of 73 fractures. Injury. 2005;36(5):605-12.

4. VanOpdorp H, Lunen BV, Swanson J. Fracture of the superomedial weight-

-bearing surface of the acetabulum in a division I field-hockey player: a case study. J Sport Rehabil. 2004;13(4):343-52.

5. Lin YC, Chen $\mathrm{CH}$, Huang HT, Chen JC, Huang PJ, Hung SH, et al. Percutaneous antegrade screwing for anterior column fracture of acetabulum with fluoroscopic-based computerized navigation. Arch Orthop Trauma Surg. 2008;128(2):223-6.

6. Stannard JP, Riley RS, Mcclenney MD, Lopez-Ben RR, Volgas DA, Alonso JE. Mechanical prophylaxis against deep-vein thrombosis after pelvic and acetabular fractures. J Bone Joint Surg Am. 2001;83(7):1047-51. 